\title{
Fe/ZSM-11 as a novel and efficient photocatalyst to degrade Dichlorvos on water solutions
}

\author{
Silvina Gomez ${ }^{\mathrm{a}, \mathrm{d}}$, Laura Lerici ${ }^{\mathrm{a}, \mathrm{d}}$, Clara Saux $^{\mathrm{a}, \mathrm{d}, *}$, Ana Laura Perez $^{\mathrm{c}, \mathrm{d}}$, \\ Carlos D. Brondino ${ }^{\mathrm{c}, \mathrm{d}}$, Liliana Pierella ${ }^{\mathrm{a}, \mathrm{d}}$, Luis Pizzio $^{\mathrm{b}, \mathrm{d}}$ \\ a Centro de Investigación y Tecnología Química (CITeQ), UTN - CONICET, Maestro Marcelo Lopez y Cruz Roja Argentina, (5016) Córdoba, Argentina \\ b Centro de Investigación y Desarrollo en Ciencias Aplicadas “Dr. J.J. Ronco" (CINDECA), Departamento de Química, Facultad de Ciencias Exactas, UNLP-CCT \\ La Plata, CONICET, 47 No 257, (1900) La Plata, Argentina \\ ${ }^{c}$ Departamento de Física, Facultad de Bioquímica y Ciencias Biológicas -UNL, Campus Universitario - Paraje El Pozo, (3000) Santa Fe, Argentina \\ d CONICET (Consejo Nacional de Investigaciones Científicas y Técnicas), Argentina
}

\section{A R T I C L E I N F O}

\section{Article history:}

Received 30 May 2016

Received in revised form 29 August 2016

Accepted 23 September 2016

Available online 24 September 2016

\section{Keywords:}

Dichlorvos

Fe/ZSM-11

Photodegradation

Heterogeneous catalysis

Stability

\begin{abstract}
A B S T R A C T
Iron modified ZSM-11 zeolites were tested as heterogeneous catalysts in the photodegradation of Dichlorvos water solutions. ZSM-11 zeolite matrixes were synthesized by the hydrothermal method and iron was incorporated by the wet impregnation method in four different concentrations. Catalysts samples were characterized by several techniques (XRD, BET, UV-vis DRS, ICP-OES, TPR, EPR) in order to confirm structure, crystallinity and iron species present. $\alpha-\mathrm{Fe}_{2} \mathrm{O}_{3}$ was detected by XRD in higher iron content samples and it presence was confirmed by EPR, TPR and UV-vis DRS. Band gap energies for Fe/ZSM-11 samples were closer to that reported for pure $\alpha-\mathrm{Fe}_{2} \mathrm{O}_{3}$. The materials so far characterized were tested as heterogeneous catalyst in Dichlorvos photodegradation. Fe/ZSM-11 with a $6 \mathrm{wt} \%$ of iron incorporation showed the best catalytic behavior. Higher iron loadings showed lower degradation efficiencies. This material is reusable for at least six catalytic cycles without considerable differences among the DDVP amount degraded.
\end{abstract}

(ㄷ) 2016 Elsevier B.V. All rights reserved.

\section{Introduction}

Owing to the wide applications of intensive agricultural techniques in the past few decades and to the fast development of agrochemical industry, the varieties and quantities of agrochemicals present in surface and ground waters have considerably increased. Most pesticides are resistant to chemical and/or photochemical degradation under natural environmental conditions [1]. Therefore, the effective removal of these pollutants from wastewater is a problem of great practical importance and interest.

Water treatment technologies applied nowadays such as adsorption, sedimentation, and membrane technologies merely concentrate the present pollutants by transferring them to other phases, but they do not eliminate pesticide residues. Other methods such as photolysis [2], adsorption [3], ozonation [4] and ultrasonic irradiation [5] have been studied for their degradation, but

\footnotetext{
* Corresponding author at: Centro de Investigación y Tecnología Química (CITeQ), UTN-CONICET, Maestro Marcelo Lopez y Cruz Roja Argentina, (5016) Córdoba, Argentina.

E-mail address: csaux@frc.utn.edu.ar (C. Saux).
}

their efficiency is not enough. All these questions have led to many research groups working in the field of "Advanced Oxidation Processes (AOP)" to research in innovative water treatment technologies based on the in situ generation of highly reactive transitory species such as $\bullet \mathrm{OH}$ for mineralization of refractory organic compounds. Among these AOP, heterogeneous photocatalysis employing semiconductor catalysts $\left(\mathrm{TiO}_{2}, \mathrm{ZnO}, \mathrm{Fe}_{2} \mathrm{O}_{3}, \mathrm{CdS}\right.$, $\mathrm{GaP}$, and $\mathrm{ZnS}$ ) appears as an emerging and cost effective technology $[6,7]$ which shows as main advantage a complete degradation of contaminants to harmless compounds such as $\mathrm{CO}_{2}$, water and inorganic salts [8]. Commercial $\mathrm{TiO}_{2}$ (Degussa $\mathrm{P}-25$ ) is one of the most popular semiconductors used as photocatalyst at laboratory scale because of its stability, low cost, and good efficiency to catalyze organic compounds degradation $[9,10]$. Nevertheless, $\mathrm{TiO}_{2}$ presents a low surface area $\left(50 \pm 15 \mathrm{~m}^{2} / \mathrm{g}\right)$, a small particle size, which difficult their recovery from the effluent wastewater, and when used in suspension, forms aggregates with lower surface area. These limitations of $\mathrm{TiO}_{2}$ as catalyst have led to look forward materials with similar efficiencies, but that possess higher specific area and particle size.

On the other hand, there are many reports involving the modification of porous adsorbents with transition metal ions used as 
photocatalysts [11]. Many materials such as silica gel, glass fibers, ceramics, cellulose membranes, polymer films, and zeolites have been tested as supports [12]. Particularly, zeolites are microporous crystalline inorganic materials capable of adsorbing organic molecules $[13,14]$. Zeolites possess a regular periodic structure with channels and cages extending all over the crystal lattice, in which the adsorption of organic guest molecules may occur on both the external and internal surfaces of the crystal. Cations (e.g. $\mathrm{Na}^{+}$) located in the zeolite cages, channels and cavities, can be exchanged for other cations. The size, number and position of the exchanged cations contribute significantly to the catalyst activity [15]. Recently, Fe(III)-doped zeolites have attracted attention of many researchers working in the field of environmental catalysis due to their activity in photo Fenton reactions. The catalytic activity of Fe(III)-doped zeolites was also investigated for photocatalytic degradation of phenol, Imidacloprid [16] and different types of azo dyes [17]. According to Mohamed et al. [18], Fe(III) ions encapsulated inside zeolites may be located into two different sites (octahedral and tetrahedral) which lead to the formation of new active sites that are responsible for the improvement of adsorption properties of these types of catalysts especially for the removal of many organic pollutants.

Dichlorvos (2,2-dichlorovinyl-o,o-dimethyl phosphate) is an insecticide used in crops, animals and pest-strips that causes the inhibition of the enzyme acetylcholinesterase, which provokes neurotoxic effects including perspiration, vomiting, diarrhea, drowsiness, fatigue, headache, and, at high concentrations, convulsions and coma after both acute (short-term) and chronic (long-term) exposure to humans. The extensive use of Dichlorvos have also increased the incidence of pancreatic, mammary glands, and fore stomach tumors in animals according the National Toxicology Program (NTP) from the United States. Furthermore, the United States Environmental Protection Agency (EPA) [19] has classified Dichlorvos as a Group B2, probable human carcinogen.

In this paper we report the synthesis, characterization and use of Fe(III)-doped ZSM-11 zeolites as active catalyst for the degradation of Dichlorvos. Fe/ZSM-11 shows a catalytic efficiency similar to that of $\mathrm{TiO}_{2}$, but has the property to expand the spectral range of absorption making it possible to employ sunlight as energy source. The aim of this study is to develop a solid catalyst capable of degrade Dichlorvos from water solutions, presenting stability in several reaction cycles and to determine its optimal reaction conditions.

\section{Experimental}

\subsection{Preparation of Fe/ZSM-11}

The Na/ZSM-11 zeolite ( $\mathrm{Si} / \mathrm{Al}=17)$ was obtained by hydrothermal crystallization in the $\mathrm{Na}_{2} \mathrm{O}-\mathrm{Al}_{2} \mathrm{O}_{3}-\mathrm{SiO}_{2}$ system, using the following reactants: silicic anhydride (Fluka), as the source of silicon, $\mathrm{NaAlO}_{2}$ (sodium aluminate, Jonhson Matthey Electronics) for aluminum and TBAOH (tetrabutylammonium hydroxide, Fluka) as template, by known methods [20]. The ammonium form of the catalyst was prepared by ion-exchange with $1 \mathrm{M}$ ammonium chloride solution at $80^{\circ} \mathrm{C}$ for $40 \mathrm{~h}$.

The iron containing zeolites (hereafter Fe/ZSM-11) were prepared by the wet impregnation method. Four different concentrations of the iron aqueous solutions $\left(\mathrm{FeSO}_{4} \cdot 7 \mathrm{H}_{2} \mathrm{O}\right.$, Cicarelli) were used to reach an $\mathrm{Fe}(\mathrm{III})$-content of 2, 6, 10 and $20 \mathrm{wt} \%$. The $\mathrm{NH}_{4}$ ZSM-11 was dispersed in the precursor aqueous solution at room temperature. Afterwards, the solvent (water) was slowly removed by rotary vacuum evaporation at $80^{\circ} \mathrm{C}$ for $20 \mathrm{~min}$. Finally, the samples were dried at $110^{\circ} \mathrm{C}$ overnight and desorbed at $500^{\circ} \mathrm{C}$ under nitrogen flow and then calcined under an oxidizing atmosphere for $8 \mathrm{~h}$.

\subsection{Catalyst characterization}

Powder XRD diffraction patterns of the materials were collected on a PANalytical X'pert PRO diffractometer equipped with $\mathrm{Cu} \mathrm{K \alpha}$ $(1.54 \AA)$ in the $2 \theta$ range $5^{\circ}-60^{\circ}$ in steps of $0.05^{\circ}$ with a count time of $2 \mathrm{~s}$ at each point. Surface area determinations from $\mathrm{N}_{2}$ adsorption-desorption isotherms using Brunauer-Emmett-Teller (BET) method were carried out with a Micromeritics ASAP 2000 equipment. UV-vis diffuse reflectance spectra (UV-vis DRS) in absorbance mode were recorded using a Jasco V 650 spectrometer in the wavelength range 200 to $900 \mathrm{~nm}$. The elemental composition of the synthesized catalysts was determined by inductively coupled plasma atomic emission spectroscopy with a VARIAN VISTA MPX - CCD simultaneous ICP-OES, previously digested in $\mathrm{H}_{2} \mathrm{SO}_{4}, \mathrm{H}_{3} \mathrm{PO}_{4}$ and HF media.

Temperature programmed reduction (TPR) studies were done over calcined Fe-containing zeolites in an Autochem 2910 Micromeritics equipment. Typically, $100-170 \mathrm{mg}$ of pelletized samples (0.2-0.4 mesh) were used in order to have a constant weight of iron in all the samples. Samples were firstly pretreated under Argon flow ( $50 \mathrm{~mL} / \mathrm{min}$ ) at room temperature during $15 \mathrm{~min}$. Then, gas flow was changed to $10 \% \mathrm{H} 2 / \mathrm{Ar}(50 \mathrm{~mL} / \mathrm{min}$.) and temperature was raised from 25 to $800^{\circ} \mathrm{C}$ at $10^{\circ} \mathrm{C} / \mathrm{min}$ using a computer-controlled program. The hydrogen uptake was monitored by means of a TCD detector connected on-line, and data will present the evolution of TCD signal in function of the increasing in temperature. Calibration of the equipment was made under same experimental conditions using $\mathrm{CuO}$ as reference sample.

Variable temperature X-band EPR measurements were performed on a Bruker EMX plus spectrometer equipped either with an Oxford nitrogen continuous-flow cryostat (100 K-room temperature) or with an Oxford helium continuous-flow cryostat (3-100 K).

Samples for EPR spectroscopy were prepared by weighting equal amounts $(8 \mathrm{mg}$ ) of powder samples of Fe/ZSM-11 and placed inside $4 \mathrm{~mm}$ inner diameter EPR quartz tubes (sample height $\sim 5 \mathrm{~mm}$ ). All tubes were placed inside the EPR spectrometer resonance cavity at the same position and measured under the same experimental conditions. Experimental conditions were field modulation, $100 \mathrm{kHz}$; modulation amplitude, $0.5 \mathrm{mT}$; microwave power, $0.2 \mathrm{~mW}$; microwave frequency, $9.46 \mathrm{GHz}$.

\subsection{Catalytic experiments}

Photodegradation experiments of Dichlorvos (DDVP Pestanal, Fluka) in water were performed in cylindrical Pyrex glass batch reactor of $18 \mathrm{~cm} \times 8 \mathrm{~cm}$ (height $\times$ diameter), provided with a water circulation arrangement to maintain the temperature in the range 25 to $30^{\circ} \mathrm{C}$. The irradiation was carried out using a $125 \mathrm{~W}$ high-pressure mercury lamp placed inside a Pyrex glass jacket thermostatized by water circulation, and immersed in the pesticide solution contained in the reactor. The catalyst was maintained in suspension by stirring and air was continuously bubbled. Previously, the DDVP solution ( $400 \mathrm{~mL}, 1 \times 10^{-4} \mathrm{M}$ ), containing $400 \mathrm{mg}$ of catalyst was stirred in the absence of light for $30 \mathrm{~min}$. Aliquots were withdrawn at specific time intervals and analyzed after filtration to remove the catalyst using a Milliporesyringe adapter (porosity, $0.22 \mu \mathrm{m}$ ). The variation of the pesticide concentration as a function of the reaction time was determined on an UV-vis Jasco 7800 double beam spectrophotometer, measuring the absorbance at $210 \mathrm{~nm}$ [21]. In some cases, high performance liquid chromatography (HPLC Perkin Elmer equipment), with a $250 \mathrm{~mm} \times 4.6 \mathrm{~mm}$ C18 reverse phase column, and a mixture of water (50\%) with acetonitrile (50\%) as solvent, $1 \mathrm{~mL} / \mathrm{min}$ flow rate, was employed. A chloride electrode (Phoenix Clo 1508-003B) was used to follow chloride ions, along the reaction period. Iron content in the liquid 
Table 1

Iron content, $\mathrm{Si} / \mathrm{Al}$ ratios, and surface area parameters $\left(\boldsymbol{S}_{\boldsymbol{B E T}}\right)$ of ZSM-11 catalysts.

\begin{tabular}{llll}
\hline Catalyst & $\mathrm{Fe}$ & $\mathrm{Si} / \mathrm{Al}$ & $\mathrm{S}_{\text {BET }}\left(\mathrm{m}^{2} / \mathrm{g}\right)$ \\
\hline $\mathrm{NH}_{4}$-ZSM-11 & - & 19.09 & 386 \\
$\mathrm{Fe} / \mathrm{ZSM}-11(2 \%)$ & 2.08 & 19.05 & 360 \\
$\mathrm{Fe} / \mathrm{ZSM}-11(6 \%)$ & 6.39 & 19.00 & 318 \\
$\mathrm{Fe} / \mathrm{ZSM}-11(10 \%)$ & 9.14 & 18.40 & 282 \\
$\mathrm{Fe} / \mathrm{ZSM}-11(20 \%)$ & 18.49 & 18.04 & 248 \\
\hline
\end{tabular}

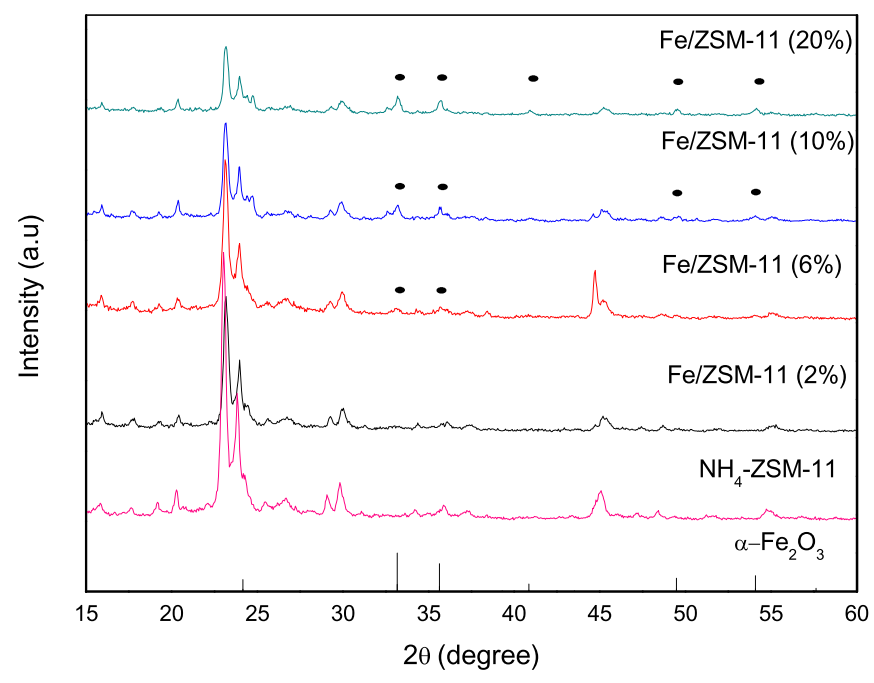

Fig. 1. XRD patterns of $\mathrm{NH}_{4}-\mathrm{ZSM}-11$ and iron modified samples.

filtrate of the degradation reactions were determined by Atomic Absorption spectrometry on a Varian AA model 240.

\section{Results and discussion}

\subsection{Catalysts characterization}

In order to confirm the effective iron incorporation into the zeolite matrix, ICP analysis were performed for all the modified samples. Table 1 summarizes the iron content and the Si/Al ratio of the materials under study. As could be observed, there is a good agreement between theoretical and the Fe amount determined by this technique.

Table 1 shows also the catalyst surface area of Fe(III)-modified zeolites determined by the BET method. This parameter is important to determine the efficiency of the material to be used as photocatalyst, since catalytic photodegradation is developed in its surface [22]. It is observed a slightly and gradually decrease in the surface area parameter values with the incorporation and the increment in iron content. This could be due to deposition of oxide particles on the zeolite matrix surface and pore blocking. A similar tendency was also reported by other authors for this kind of transition metal-modified materials [23].

X-Ray Diffraction (XRD) studies were performed to determine the presence of metal species or oxides deposited on the support and to confirm the crystallinity and structure of the Fe/zeolite catalysts. Fig. 1 shows XRD diffraction patterns of the $\mathrm{NH}_{4}-\mathrm{ZSM}-11$ together with those of $\mathrm{Fe}$ (III)-doped (from 2 to $20 \mathrm{wt} \%$ ) modified zeolites. After the metal incorporation process the zeolite structure was preserved since the analysis of the XRD patterns indicates that the Fe-zeolites have crystallinity almost identical to that of the parent $\mathrm{NH}_{4}-\mathrm{ZSM}-11$. Diffraction signals at $2 \theta$ equal to $7^{\circ}, 9^{\circ}, 23^{\circ}$, and $24^{\circ}$, were detected in all the samples and are assigned to the (1 0 1), (2 00 0), (3 3 2), and (3 03 3) crystal planes, respectively [24]. The signals at $2 \theta 33.5,35.5,49$ and $54^{\circ}$ can be assigned to $\alpha-\mathrm{Fe}_{2} \mathrm{O}_{3}$

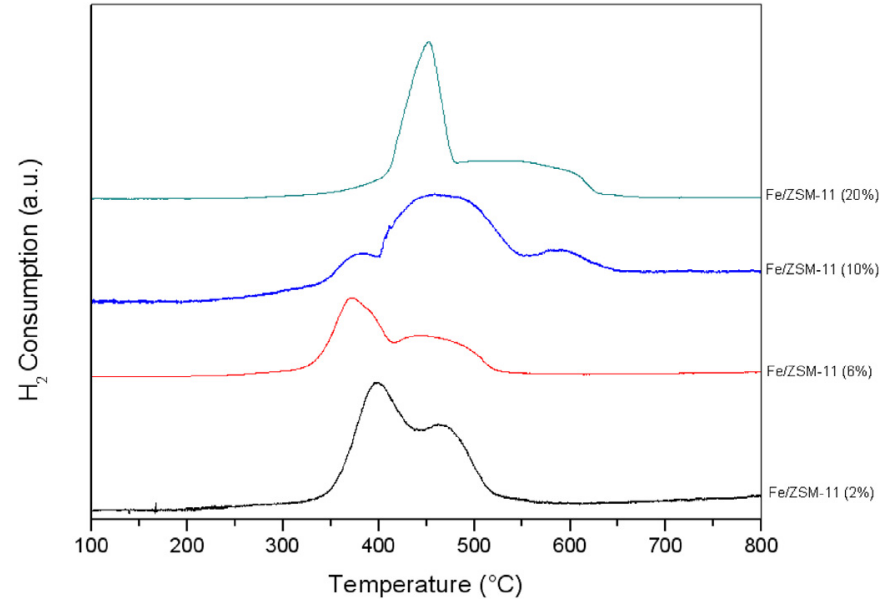

Fig. 2. TPR profiles of the Fe/ZSM-11 samples.

phase (hematite, PDF \#33-0644) [25,26]. These peaks were solely found in higher iron content zeolites. The absence of other hematite signals in lower iron content samples could be attributed either to the high dispersion of these species in the channels and cavities of the zeolites, or to a significantly small oxide particle size [15]. In the case of Fe/ZSM-11 (2\%) sample the absence of signals corresponding to $\alpha-\mathrm{Fe}_{2} \mathrm{O}_{3}$ may be explained since the supported $\mathrm{FeOx}$ nanoparticles are too small to be detected by XRD [27].

The slight reduction in intensity of the ZSM-11 characteristic peaks at higher iron concentrations could be attributed to a dilution effect of the zeolite matrix in the catalyst considering a greater proportion of metal species (higher Fe/Si molar ratio) [16].

The reducibility of metal species is a powerful tool to analyze metal - support interaction. Fig. 2 shows the results of $\mathrm{H}_{2}$-TPR measurements obtained for iron modified ZSM-11 zeolites after calcination treatment (further information Table 1, Supplementary material). Samples with low metal content (2 and 6 Fe wt\%) presented similar TPR profiles with two peaks centered at 375 and $475^{\circ} \mathrm{C}$ that could be assigned to $\mathrm{Fe}_{2} \mathrm{O}_{3} \rightarrow \mathrm{Fe}_{3} \mathrm{O}_{4}$ and $\mathrm{Fe}_{3} \mathrm{O}_{4} \rightarrow \mathrm{FeO}$, respectively [28]. In contrast, $\mathrm{Fe} / \mathrm{ZSM}-11(10 \%)$ sample showed three reduction peaks at 375,475 and $600^{\circ} \mathrm{C}$. The first two peaks correspond to the reduction process $\mathrm{Fe}_{2} \mathrm{O}_{3} \rightarrow \mathrm{Fe}_{3} \mathrm{O}_{4} \rightarrow \mathrm{FeO}$, whereas the third one was assigned to $\mathrm{FeO} \rightarrow \mathrm{Fe}^{0}$ reduction [29]. Two peaks centered at 475 and $600^{\circ} \mathrm{C}$ were observed for Fe/ZSM-11 (20\%), which were attributed to the $\mathrm{Fe}_{3} \mathrm{O}_{4} \rightarrow \mathrm{FeO} \rightarrow \mathrm{Fe}^{0}$ reduction process. Considering that iron oxides reductions are typically carried out at temperatures lower than $400^{\circ} \mathrm{C}$ [30], the shift of the peaks to higher reduction temperatures could be due to an stabilization effect by the zeolite support.

The UV-vis DRS spectrum of $\mathrm{NH}_{4}-\mathrm{ZSM}-11$ presents a band at $200 \mathrm{~nm}$ assigned to Al-O charge-transfer transition of four-coordinated framework aluminum. The shoulder at $250 \mathrm{~nm}$ was assigned to structures with highly ordered octahedral symmetry [31].

According to literature $[32,33]$ isolated $\mathrm{Fe}^{3+}$ ions incorporated into the matrix in tetrahedral and octahedral coordination show charge transfer bands of oxygen atoms $\left(\mathrm{O}^{2-} \rightarrow \mathrm{Fe}^{3+}\right)$ at 220 and $285 \mathrm{~nm}$, respectively. The last band can clearly be detected in the UV-vis DRS spectra of the Fe/ZSM-11 samples, as long as the band at 220 is overlapped to the Al-O charge-transfer zeolite characteristic band (Fig. 3).

Additionaly, Fe incorporation produces an increase of the absorbance of the Fe/ZSM-11samples in the $300-600 \mathrm{~nm}$ region. This increment can be due to the overlap of the band at $350 \mathrm{~nm}$ assigned to $\mathrm{Fe}^{3+}$ ions forming oligonuclear clusters in extra-framework positions [34], and the absorption features (at 


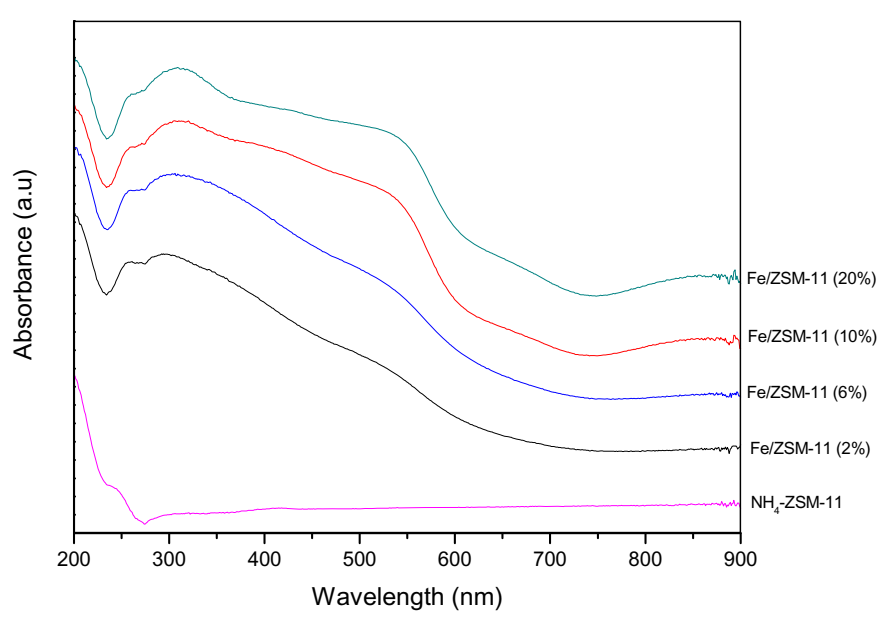

Fig. 3. UV-vis DR spectra of $\mathrm{NH}_{4}-\mathrm{ZSM}-11$ and Fe/ZSM-11 samples.

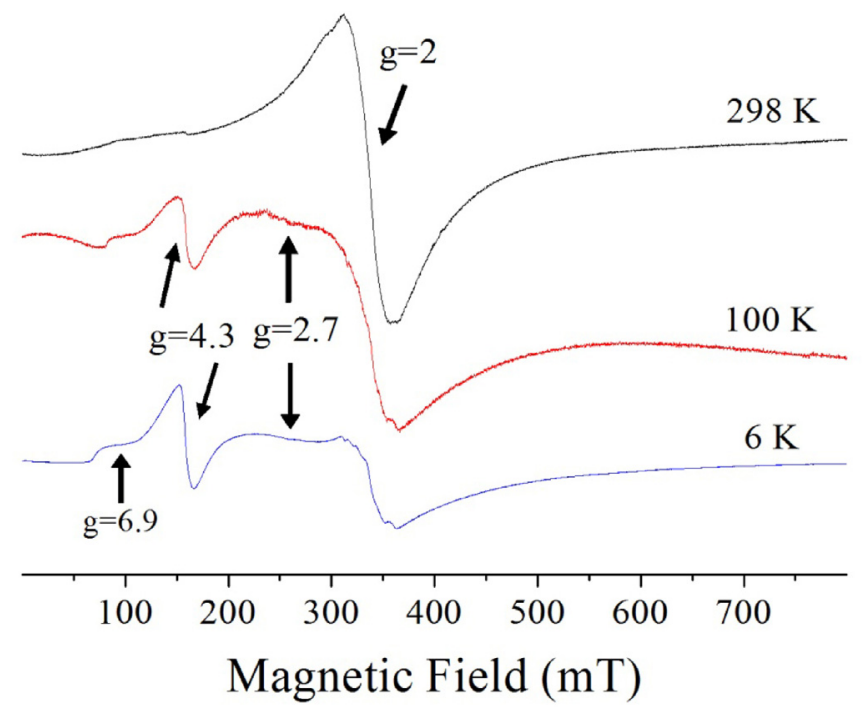

Fig. 4. EPR spectra of Fe/ZSM-11 (6\%) at room temperature, $100 \mathrm{~K}$, and $6 \mathrm{~K}$.

wavenumbers higher than $450 \mathrm{~nm})$ to large iron oxide $\left(\alpha-\mathrm{Fe}_{2} \mathrm{O}_{3}\right)$ particles localized on the zeolite surface [35]. On the other hand, as result of Fe content increment, the absorption between 300 and $650 \mathrm{~nm}$ increases, which is associated with a higher proportion of oligonuclear clusters and oxide nanoparticles [14].

Band gap energies for iron-containing samples $(1.9 \pm 0.6 \mathrm{eV})$ determined from DRS spectra employing Kubelka - Munk function [36] (Fig. 1, Supplementary material) were similar to those reported for $\alpha-\mathrm{Fe}_{2} \mathrm{O}_{3}(2.2 \mathrm{eV})$ [37]. As reported by Noorjahan et al. [38], with an increase in the Fe content there is an increase in the number of energy levels resulting in a decrease in the band gap, falling closer to that of pure Fe-oxide.

The results obtained by UV-vis DR spectroscopy were complemented with EPR to obtain further information on both oxidation states and geometry of coordination of the iron ions incorporated into ZSM-11 zeolites.

Fig. 4 shows representative EPR spectra of iron-doped ZSM-11 zeolites taken at different temperatures. As shown in this figure, spectra present three different superposed components associated with high spin $\mathrm{Fe}(\mathrm{III})$ ions $(S=5 / 2)$ which are identified with the most representative $g$-value $(g=2.0,2.7,4.3)$. The $g=2.0$ component shows a nearly Lorentzian line shape with $g=2.019$ and a peak to peak line width of $59.1 \mathrm{mT}$, whereas, the $\mathrm{g}=2.7$ present a broad resonance with no well distinguishable lineshape. Both



Fig. 5. EPR spectra taken at different temperatures of Fe/ZSM-11 (6\%). The distinct EPR spectral components are identified with representative $g$ values.

$\mathrm{g}=2.0$ and $\mathrm{g}=2.7 \mathrm{EPR}$ signals have been assigned to antiferromagnetically coupled $\mathrm{Fe}(\mathrm{III})$ oxides $\left(\alpha-\mathrm{Fe}_{2} \mathrm{O}_{3}, \gamma-\mathrm{Fe}_{2} \mathrm{O}_{3}\right.$ and $\left.\mathrm{FeO}(\mathrm{OH})\right)$ located in both pores and surface of zeolites [39-41]. The $\mathrm{g}=4.3$ spectral component consists of a main EPR resonance line at $\mathrm{g}=4.3$ plus a shoulder at $\mathrm{g} \sim 6.9$, typical of a mononuclear high spin $\mathrm{Fe}(\mathrm{III})$ center possessing a large zero-field splitting $(D>0)$ with distinct degrees of distortion [42]. This signal is attributed to isolated Fe(III) ions incorporated into the zeolite lattice in tetrahedral or octahedral coordination.

The EPR signal at $\mathrm{g}=4.3$ is observed in all the temperature range, though its presence is more noticeable at temperatures lower than $240 \mathrm{~K}$ (Fig. 5). The intensity of this spectral component follows approximately a Curie's behavior in the temperature range of room temperature $-200 \mathrm{~K}$, whereas at lower temperatures the intensity is smaller than that predicted by Curie's law, as previously observed for Fe(III)-doped ZSM-5 zeolites [43]. This behavior is consistent with the well-known fact that the $g=4.3$ resonance arises from the transition within the middle doublet of the $\mathrm{m}_{\mathrm{S}}$ manifold of high spin $\mathrm{Fe}(\mathrm{III})$ species [42]. The intensity of the $\mathrm{g}=2.7$ spectral component is roughly constant in all the temperature range. In contrast, the intensity of the $g=2$ component decreases with decreasing temperatures, which confirms the antiferromagnetic behavior of the extralattice oxidic Fe(III) particles (Fig. 5).

Fig. 6 shows the variation of the room temperature $g=2$ EPR signal intensity as a function of the $\mathrm{Fe}(\mathrm{III})$ concentration in the ZSM-11 zeolite lattice. As shown in this figure, there is a lineal relationship between the $\mathrm{g}=2$ chemical species and the zeolite $\mathrm{Fe}(\mathrm{III})$ concentration. In contrast, the $\mathrm{g}=2.7$ and $\mathrm{g}=4.3 \mathrm{EPR}$ signals show approximately the same intensity in all the iron concentration range (data not shown). These results altogether indicate that zeolites have a maximum capacity to incorporate intralattice $\mathrm{Fe}(\mathrm{III})$ ions, which is saturated even at the lowest Fe(III)-doped concentration (2\%), and that the $\mathrm{Fe}(\mathrm{III})$ ion remnant accumulates as oxidic extralattice particles with $g=2.0$. This EPR observation is in agreement with that obtained from UV-vis DRS, since the absorbance of the band assigned to isolated Fe(III) species in tetrahedral coordination or octahedral coordination (220 and $285 \mathrm{~nm}$ respectively), did not increase with the increment of iron content in the support, while the bands at wavenumbers higher than $300 \mathrm{~nm}$, assigned to $\mathrm{Fe}^{3+}$ ions forming oligonuclear clusters in extra-framework posi- 


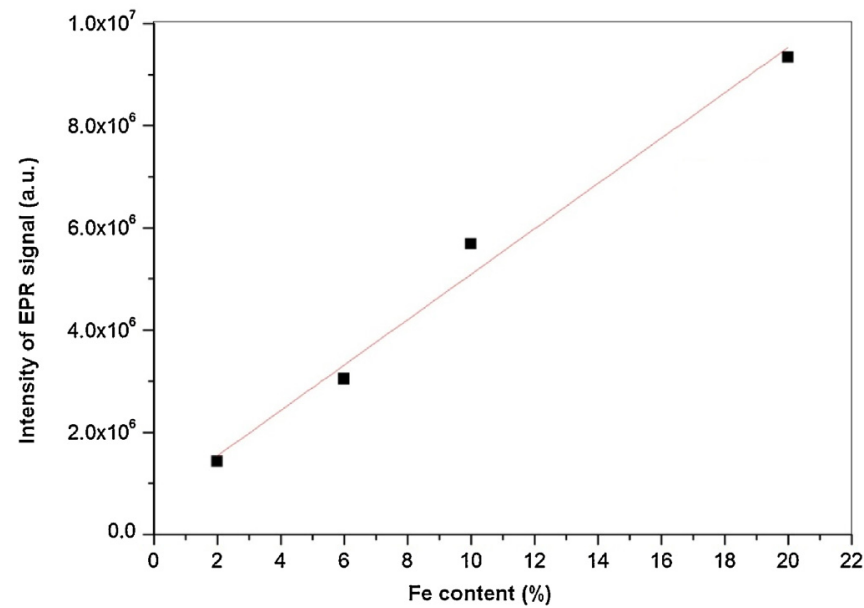

Fig. 6. $g=2$ EPR signal intensity of Fe/ZSM-11samples as function of iron content at room temperature.

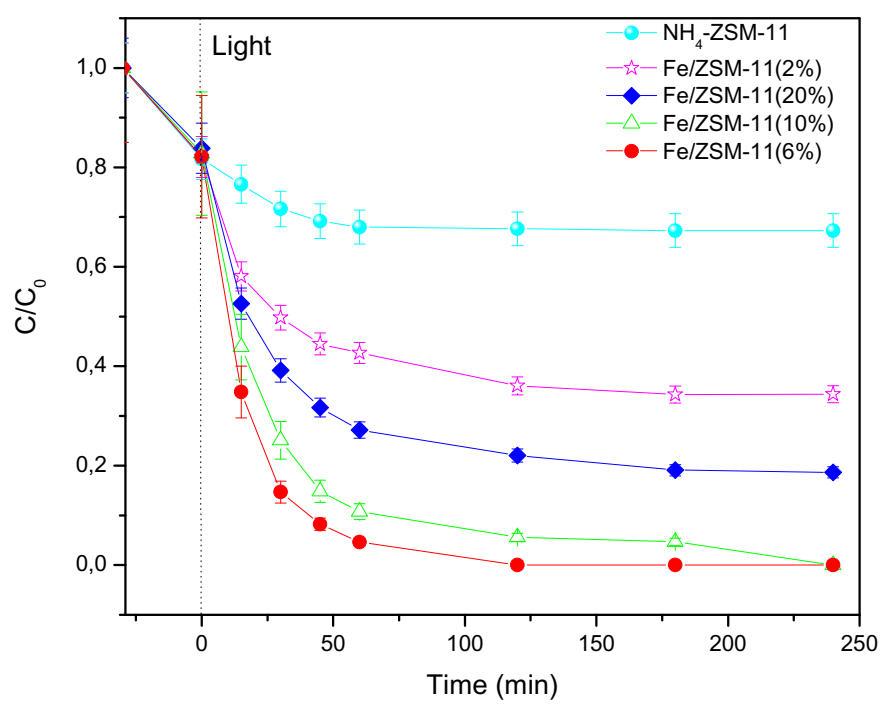

Fig. 7. DDVP photodegradation over ZSM-11 modified matrices.

tion and large iron oxide $\left(\alpha-\mathrm{Fe}_{2} \mathrm{O}_{3}\right)$ particles, showed a progressive increment with $\mathrm{Fe}(\mathrm{III})$-doped concentration loading in the support.

\subsection{Catalytic activity}

In order to determine Fe loading effect in Fe/ZSM-11 catalytic activity for Dichlorvos (DDVP) photodegradation, a series of experiments were performed (Fig. 7). The unmodified matrix did not show any photocatalytic behavior since around a 15\% of adsorption of the pesticide was obtained without light irradiation and not considerable changes were obtained under it. In the case of iron modified ZSM-11 samples, after 240 min of reaction over a $50 \%$ of contaminant concentration reduction was obtained. When iron loading increases from 2 to 6\%, DDVP degradation rate enhances; but when higher Fe loadings (10 and 20\%) were employed, degradation results were poorer than those obtained for Fe/ZSM-11 (6\%). This behavior could be attribute to a pore blockage because of the higher iron content, that produces a lower surface area and so a lower insect ice absorbance capacity.

The catalytic activity towards DDPV seems to be associated with both lattice and extralattice Fe(III) ions. According to the UV-vis DRS and EPR results, the chemical species that increases their concentration upon $\mathrm{Fe}$ (III)-doped content raises are only the

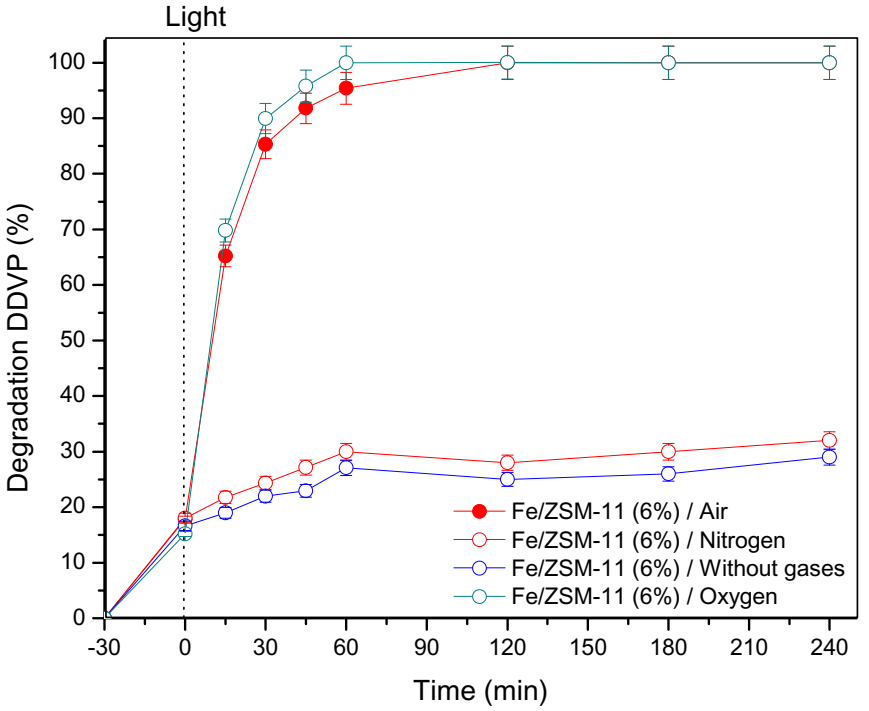

Fig. 8. Bubbling gases effect in DDVP degradation.

extralattice $\mathrm{Fe}(\mathrm{III})$ species with $\mathrm{g}=2$. The role of the $\mathrm{g}=2.7$ species in catalysis is less clear as no significant variations with Fe(III)-doped concentration were detected, but the fact that their zeolite incorporation is similar to that of $\mathrm{g}=4.3$ species, suggests that it might also play a role in catalysis.

Water molecules adsorbed near iron ions easily react in order to generate $\bullet \mathrm{OH}$ radicals, which are responsible of the photoreaction initiation and the fast contaminant degradation [17]. Taking into account the iron species present in the synthesized Fe/zeolites and the employed $\mathrm{pH}$ range ( $\mathrm{pH} 3.5-5$ ), the proposed reactions are [44]:

$\mathrm{Fe}^{3+}+\mathrm{H}_{2} \mathrm{O} \rightarrow \mathrm{Fe}(\mathrm{OH})^{2+}+\mathrm{H}^{+}$

$\mathrm{Fe}(\mathrm{OH})^{2+}+\mathrm{hv} \rightarrow \mathrm{Fe}^{2+}+\cdot \mathrm{OH}$

That leads to:

$\mathrm{Fe}^{3+}+\mathrm{H}_{2} \mathrm{O}+\mathrm{h} v \rightarrow \mathrm{Fe}^{2+}+\cdot \mathrm{OH}+\mathrm{H}^{+}$

This fast initial step of the photodegradation process produces a fast depletion of the monomer $\mathrm{Fe}(\mathrm{OH})^{2+}$ and a substantial quantity of $\mathrm{Fe}^{3+}$ is converted to $\mathrm{Fe}^{2+}[45]$. Thus, to maintain higher degradation levels, but employing lower $\mathrm{Fe}^{3+}$ concentrations, simultaneous $\mathrm{Fe}^{2+}$ to $\mathrm{Fe}^{3+}$ oxidation could be an effective alternative [46]. Dioxygen is well known to be a cheap oxidant capable of maintaining a constant $\mathrm{Fe}^{+2} / \mathrm{Fe}^{+3}$ ratio, according to:

$\mathrm{Fe}^{2+}+\mathrm{O}_{2} \rightarrow \mathrm{Fe}^{3+}+{ }^{-} \mathrm{O}_{2}^{-}$

To evaluate its influence in the degradation process, the reaction was performed with oxygen, air or nitrogen bubbling and without gases. The obtained results, which are presented in Fig. 8, confirmed the promoting effect of the oxidant presence. Furthermore, molecular oxygen improves degradation rate and efficiency of organic substrates, since it trapps electrons from the conduction band of the catalyst, avoiding its recombination with the hole [47]:

$\mathrm{O}_{2}+\mathrm{e}^{-} \rightarrow \cdot \mathrm{O}_{2}^{-}$

with the formed ${ }^{\bullet} \mathrm{O}_{2}{ }^{-}$radical being an active oxidant that could attack neutral substrates.

When a hole and an electron are generated on the catalyst surface, the electron should be quickly removed to prevent the electron-hole recombination and thus to maintain suitable hole concentration that promote the oxidation process.

As could be seen from Fig. 8, when oxygen was bubbled in the solution (air and oxygen bubbled gases experiences), DDVP complete degradation was reached after the first reaction hour, while 
in oxygen free conditions (without gases and nitrogen bubbled experiences), a plateau of $30 \%$ in the pollutant degradation was achieved. Oxygen appeared to be a key factor, since $\mathrm{Fe}^{+2} / \mathrm{Fe}^{+3}$ conversion (Reaction 4 ) does not take place in its absence, limiting the contaminant conversion.

Another Fe specie found in the synthesized samples was the $\alpha$ $\mathrm{Fe}_{2} \mathrm{O}_{3}$ that generates electrons in the conduction band and holes in the valence band when irradiated with energy higher than the band gap $(\mathrm{Eg}=2.2 \mathrm{eV})[48]$. The hole in the valence band produces hydroxil radicals from water oxidation in the catalyst surface, while the electron in the conduction band reduces the oxygen in the catalyst surface, generating the superoxide radical [47]:

$$
\begin{aligned}
& \alpha-\mathrm{Fe}_{2} \mathrm{O}_{3}+\mathrm{h} v \rightarrow \mathrm{e}^{-}+\mathrm{h}^{+} \\
& \mathrm{H}_{2} \mathrm{O}+\mathrm{h}^{+} \rightarrow \cdot \mathrm{OH}+\mathrm{H}^{+} \\
& \mathrm{O}_{2}+\mathrm{e}^{-} \rightarrow \cdot \mathrm{O}_{2}^{-}
\end{aligned}
$$

Thus, both Fe species found in the synthesized catalysts generate - $\mathrm{OH}$ radicals that improbes the organic contaminant degradation allowing to get a complete mineralization.

\subsubsection{Catalyst concentration effect}

The effect of catalyst mass in DDVP degradation was studied in the $200-2000 \mathrm{mg} / \mathrm{L}$ concentration range employing Fe/ZSM-11 (6\%) and keeping constant the other reaction parameters (Fig. 2, Supplementary material). It is possible to observe an increasing degradation trend until $1000 \mathrm{mg} / \mathrm{L}$, but at higher catalyst concentrations no further improvement was observed, probably due to a light dispersion effect because of the turbidity and opacity of the solution when the solution has a higher catalyst particles content [21]. In the case of iron based catalyst, another cause for this behavior could be that the $\mathrm{Fe}^{2+}$ species attack the oxidant radicals [49]:

$\mathrm{Fe}^{2+}+\cdot \mathrm{OH} \rightarrow \mathrm{Fe}^{3+}+\mathrm{OH}^{-}$

resulting in a lower ${ }^{\bullet} \mathrm{OH}$ concentration that causes a detriment in the insecticide degradation. According to these results, an optimal catalyst concentration of $1000 \mathrm{mg} / \mathrm{L}$ is necessary to obtain a maximum pesticide reduction.

\subsubsection{Iron leaching}

The advanced oxidation process employing iron photocatalysts has extensively been investigated in many organic contaminants degradations [50]. Recently, many papers has been published employing supported iron catalysts [38], but a key factor to be solved is the leaching of Fe ions in the treated water that provokes a catalyst deactivation and causes an additional contamination.

In order to evaluate the catalyst stability and reusability, the catalytic activity under six reaction cycles was evaluated. After each experiment the catalyst was removed by filtration, washed with distilled water and dried at $110^{\circ} \mathrm{C}$ for $12 \mathrm{~h}$. No additional thermal treatments were used after each reaction cycle. The obtained results (Fig. 3, Supplementary material) confirm the catalyst reusability as the activity remained almost constant for six consecutive reaction cycles.

A slight reduction in the degradation percentage (about 5\%) after the sixth reaction cycle is probably due to the organic intermediary accumulation in the zeolite cavities affecting its adsorption capacity and activity. Thus, it is possible to state that Fe/ZSM-11 materials are active and stable catalysts for DDVP photodegradation.

Iron content in the solids before their use as catalyst in the reaction was determined by ICP and the results are shown in Table 2. Its leaching from the material was calculated for each situation as $\mathrm{Fe} \%$. After remove the catalyst by filtration of the reaction media, iron content in the filtrate solution was determined by Atomic
Table 2

Iron content in the catalysts.

\begin{tabular}{llll}
\hline Entry & Catalyst & $\begin{array}{l}\text { Initial Fe } \\
\text { content }^{\mathrm{a}}\end{array}$ & $\begin{array}{l}\text { Fe\% leached in the } \\
\text { reaction solution }\end{array}$ \\
\hline 1 & Fe/ZSM-11(2\%) & 2 & 0.5 \\
2 & Fe/ZSM-11(6\%) & 6.39 & 1.3 \\
3 & Fe/ZSM-11(6\%)-2nd use & 6.31 & 0.6 \\
4 & Fe/ZSM-11(6\%)-3th use & 6.27 & 0.3 \\
5 & Fe/ZSM-11(6\%)-4th use & 6.25 & 0.3 \\
6 & Fe/ZSM-11(6\%)-5th use & 6.23 & 0.3 \\
7 & Fe/ZSM-11(6\%)-6th use & 6.21 & 0.3 \\
8 & Fe/ZSM-11(10\%) & 9.14 & 4.1 \\
9 & Fe/ZSM-11(20\%) & 18.49 & 7.4 \\
\hline
\end{tabular}

a By ICP in the initial solid.

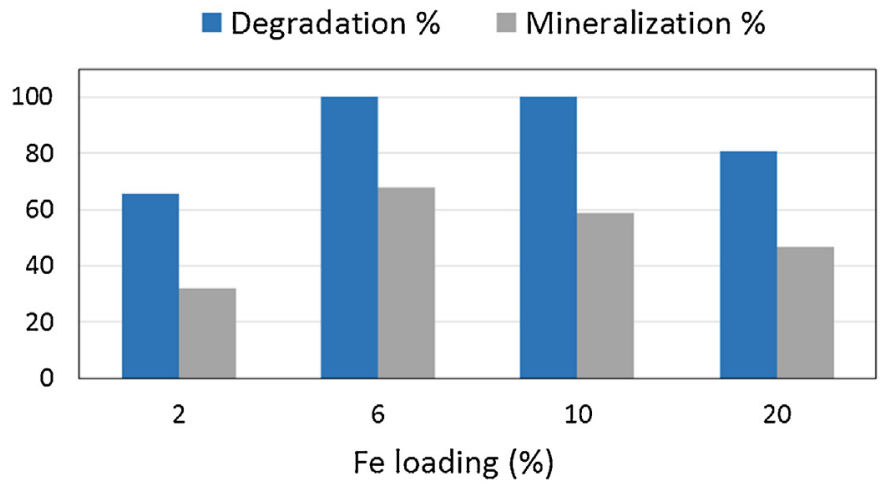

Fig. 9. DDVP degradation and mineralization reached after $240 \mathrm{~min}$ as function of wt\% Fe content in the ZSM-11 support.

Absorption. For Fe/ZSM-11 (2\%) and (6\%) samples, iron content in the filtrate after $240 \mathrm{~min}$ of reaction was less than $1 \mathrm{ppm}$. But 3.8 and $13.7 \mathrm{ppm}$ of Fe was determined for $(10 \%)$ and (20\%) samples, respectively.

In all the cases, the maximum iron amount leached in a catalytic run was lower than $8 \%$ (Fe/ZSM-11 (20\%)). The Fe/ZSM-11 (6\%) shows a $1.3 \%$ of leaching after the first use, but this value goes down in further reuses. This indicates that the catalyst can be employed repeatedly without significant active phase loss. These observations alow us to present Fe/ZSM-11 (6\%) as an optimal catalyst for this reaction.

\subsubsection{Mineralization analysis}

Total organic carbon determinations (TOC) were carried out to estimate the pesticide mineralization as a function of iron content in the catalyst (Fig. 9). This experiment shows that for all the materials tested, the DDVP mineralization percentage was lower than the DDVP degradation percentage. These results suggest the presence of degradation intermediaries. Although the nature of these organic intermediaries was not evaluated, mineralization results allow us to suggest that 0,0,0-trimethyl phosphoric ester and 0,0-dimethyl phosphonic ester are present, in accordance with literature[51]. It should be noted that both of them are less toxic than DDVP.

The reactions were also followed by a chloride electrode, the potential measurements confirmed degradation and mineralization results. In all the cases chloride ions concentrations showed a fast generation during the first reaction period and further remained almost constant. These results showed that chloride ions liberation is a fast step, probably responsible of the DDVP signal disappearance in accordance with previous results [52]. 


\section{Conclusions}

Water solutions containing Dichlorvos $\left(1 \times 10^{-4} \mathrm{M}\right)$ were efficiently treated employing a photocatalytic system that consists in a batch reactor operated at room temperature and irradiated with a $125 \mathrm{~W}$ high-pressure mercury lamp. ZSM-11 zeolites modified by iron incorporation in different percentages were tested as catalysts for this reaction.

Iron containing ZSM-11 zeolites mantained their cristallinity and structure after chemical and thermal treatments applied, according to characterization results. By XRD a $\mathrm{Fe}_{2} \mathrm{O}_{3}$ signal was detected indicating that ferrous species are oxidize along zeolite surface during calcination process. UV-vis DRS results present $\alpha$ $\mathrm{Fe}_{2} \mathrm{O}_{3}$ bands and when iron loading was increased, lower band gaps were obtained for Fe/samples.

The best catalytic behavior in order to degradate DDVP was reached when Fe/ZSM-11 (6\%) was employed. Higher iron loadings showed lower efficiencies since a pore blockage was produced, lowering surface areas and so decreasing insectice adsorbance capacity, resulting in a reduction of the photocatalytic degradation.

Fe/ZSM-11 (6\%) showed high cristallinity, appropiate surface area and considerable stability under reaction conditions, mantaining its degradation properties almost unchanged after six reaction cycles. All these features makes it an optimal heterogeneous catalyst for DDVP degradation.

\section{Acknowledgements}

The authors thank Dr. Marcelo Domine from ITQ for TPR measurements of the samples.

This project was partially supported by: FONCYT PICT 20131615 and UTN PID 2099 and $25 \mathrm{E} / 172$. We would also wish to thank CONICET.

\section{Appendix A. Supplementary data}

Supplementary data associated with this article can be found, in the online version, at http://dx.doi.org/10.1016/j.apcatb.2016. 09.047.

\section{References}

[1] R.S. Juang, C.H. Chen, J. Taiwan Inst. Chem. Eng. 45 (2014) 989-995.

[2] W. Han, P. Zhang, W. Zhu, J. Yin, L. Li, Water Res. 38 (2004) 4197-4203.

[3] H.M. Baker, R. Ghanem, Desalination 249 (2009) 1265-1272.

[4] J. Vittenet, J. Rodriguez, E. Petit, D. Cot, J. Mendret, A. Galarneau, S. Brosillon, Microporous Mesoporous Mater. 189 (2014) 200-209.

[5] J.D. Schramm, I. Hua, Water Res. 35 (2001) 665-674.

[6] M.N. Chong, B. Jin, C.W.K. Chow, C. Saint, Water Res. 44 (2010) 2997-3027.

[7] V. Elías, E. Vaschetto, K. Sapag, M. Oliva, S. Casuscelli, G. Eimer, Catal. Today 172 (2011) 58-65.

[8] A. Tomašević, E. Kiss, S. Petrović, D. Mijin, Desalination 262 (2010) 228-234.

[9] A. Mills, J. Wang, D.F. Ollis, J. Catal. 243 (2006) 1-6.

[10] M.L. Satuf, R.J. Brandi, A.E. Cassano, O.M. Alfano, Ind. Eng. Chem. Res. 44 (2005) 6643-6649.-
[11] L. Davydov, E.P. Reddy, P. France, P.G. Smirniotis, J. Catal. 203 (2001) 157-167.

[12] R.L. Pozzo, M.A. Baltanás, A.E. Cassano, Catal. Today 39 (1997) 219-231.

[13] M.B. Kasiri, H. Aleboyeh, A. Aleboyeh, Appl. Catal. B Environ. 84 (2008) 9-15.

[14] R. Prihod'ko, I. Stolyarova, G. Gündüz, O. Taran, S. Yashnik, V. Parmon, V. Goncharuk, Appl. Catal. B Environ. 104 (2011) 201-210.

[15] A.K. Aboul-Gheit, S.M. Ahmed, S.A. Hanafy, J. Mol. Catal. A Chem. 288 (2008) $52-57$.

[16] R. Gonzalez-Olmos, M.J. Martin, A. Georgi, F.D. Kopinke, I. Oller, S. Malato, Appl. Catal. B Environ. 125 (2012) 51-58.

[17] H. Hassan, B.H. Hameed, Desalination 276 (2011) 45-52.

[18] M.M. Mohamed, N.S. Gomaa, M. El-Moselhy, N.A. Eissa, J. Colloid Interface Sci. 259 (2003) 331-337.

[19] Https://www3. epa.gov.

[20] L.B. Pierella, S. Renzini, O.A. Anunziata, Microporous Mesoporous Mat. 81 (2005) 155-159.

[21] M. Qamar, M. Saquib, M. Muneer, Dye. Pigment. 65 (2005) 1-9.

[22] A.P. Davis, C.P. Huang, Langmuir 7 (1991) 709-713.

[23] S.A. Regenhardt, C.I. Meyer, A.F. Trasarti, A. Monzón, T.F. Garetto, Chem. Eng. J. 198-199 (2012) 18-26.

[24] M.S. Renzini, U. Sedran, L.B. Pierella, J. Anal. Appl. Pyrolysis 86 (2009) 215-220

[25] Z. Zhang, M.F. Hossain, T. Takahashi, Appl. Catal. B Environ. 95 (2010) 423-429.

[26] G. Moretti, G. Fierro, G. Ferraris, G.B. Andreozzi, V. Naticchioni, J. Catal. 318 (2014) 1-13.

[27] P. Xie, Y. Luo, Z. Ma, C. Huang, C. Miao, Y. Yue, W. Hua, Z. Gao, J. Catal. 330 (2015) 311-322

[28] A. Guzmán-Vargas, G. Delahay, B. Coq, E. Lima, P. Bosch, J.C. Jumas, Catal. Today 107-108 (2005) 94-99.

[29] B. Coq, M. Mauvezin, G. Delahay, S. Kieger, J. Catal. 195 (2000) 298-303.

[30] H. Topsøe, J.A. Dumesic, M. Boudart, J. Catal. 28 (1973) 477-488.

[31] M.A. Zanjanchi, A. Razavi, Spectrochim. Acta - Part A Mol. Biomol. Spectrosc. 57 (2001) 119-127.

[32] M.S. Kumar, Thesis (2005).

[33] Y. Lu, J. Zheng, J. Liu, J. Mu, Microporous Mesoporous Mat. 106 (2007) 28-34.

[34] E.J.M. Hensen, Q. Zhu, M.M.R.M. Hendrix, A.R. Overweg, P.J. Kooyman, M.V. Sychev, R.A. Van Santen, J. Catal. 221 (2004) 569-583.

[35] M.M. Mohamed, I.O. Ali, N.A. Eissa, Microporous Mesoporous Mat. 87 (2005) 93-102.

[36] S.P. Tandon, J.P. Gupta, Phys. Status Solidi B 38 (1970) 363-367.

[37] A. Boudjemaa, S. Boumaza, M. Trari, R. Bouarab, A. Bouguelia, Int. J. Hydrogen Energy 34 (2009) 4268-4274.

[38] M. Noorjahan, V. Durga Kumari, M. Subrahmanyam, L. Panda, Appl. Catal. B Environ. 57 (2005) 291-298.

[39] G. Calis, P. Frenken, E. de Boer, A. Swolfs, M.A. Hefni, Zeolites 7 (1987) 319-326.

[40] P. Fejes, J.B. Nagy, K. Lázár, J. Halász, Appl. Catal. A Gen. 190 (2000) 117-135.

[41] A.M. Ferretti, L. Forni, C. Oliva, A. Ponti, Res. Chem. Intermed. 28 (2002) $101-116$.

[42] J.R. Pilbrow, Transition ion electron paramagnetic resonance, Clarendon (1990).

[43] A. Brückner, R. Lück, W. Wieker, B. Fahlke, Zeolites 12 (1992) 380-385.

[44] O. Bajt, G. Mailhot, M. Bolte, Appl. Catal. B Environ. 33 (2001) 239-248.

[45] G. Mailhot, L. Hykrdová, J. Jirkovský, K. Lemr, G. Grabner, M. Bolte, Appl. Catal. B Environ. 50 (2004) 25-35.

[46] M. Rodríguez, N.B. Abderrazik, S. Contreras, E. Chamarro, J. Gimenez, S. Esplugas, Appl. Catal. B Environ. 37 (2002) 131-137.

[47] N.F. Jaafar, A. Abdul Jalil, S. Triwahyono, M.N. Muhd Muhid, N. Sapawe, M.A.H Satar, H. Asaari, Chem. Eng. J. 191 (2012) 112-122.

[48] I. Poulios, I. Tsachpinis, J. Chem. Technol. Biotechnol. 74 (1999) 349-357.

[49] J. Chen, L. Zhu, Catal. Today 126 (2007) 463-470.

[50] M.M. Emara, A.S.M. Tourky, M.M. El-Moselhy, J. Hazard. Mater. 166 (2009) $514-522$.

[51] E. Evgenidou, I. Konstantinou, K. Fytianos, T. Albanis, J. Hazard. Mater. 137 (2006) 1056-1064.

[52] E. Evgenidou, K. Fytianos, I. Poulios, Appl. Catal. B Environ 59 (2005) 81-89. 